\title{
Smoking and Body Mass in the Natural History of Physical Activity: Prospective Evidence from the Alameda County Study, 1965-1974
}

\author{
Nancy B. Lazarus, MD, MPH, George A. Kaplan, PhD, \\ Richard D. Cohen, MA, and Diing-Jen Leu, MPH
}

\begin{abstract}
The prospective effects of smoking status and body mass on change in leisure-time physical activity from 1965 to 1974 were examined in a cohort of 4,622 persons $20-94$ years of age from the Alameda County Study. With adjustment for age and baseline physical activity, current smokers showed a greater nine-year decline in leisure-time physical activity than those who had never smoked. The coefficient for current smokers from a multivariate linear regression model was of a similar magnitude among women and men (coefficient $=-0.27,95 \%$ confidence interval $[\mathrm{CI}]=-0.50$ to -0.05 for women; coefficient $=-0.26,95 \% \mathrm{CI}=-0.54$ to 0.02 for men). Larger declines in physical activity were seen with increasing number of current pack-years exposure among both women and men. Compared with women of average body mass index, women of heaviest body mass index had larger declines (coefficient $=-0.70$, $95 \% \mathrm{CI}=-1.04$ to -0.36 ) while women of the lightest body mass index had larger increases (or smaller declines) in physical activity (coefficient $=0.33,95 \% \mathrm{CI}=0.00$ to 0.66 ). Although body mass index did not initially appear to be associated with a change in physical activity among men, age-specific analyses indicated that the effect of body mass index on physical activity varied with age such that younger (20-39 years of age), thinner men increased their activity, while older (60 years of age and over), thinner men decreased their physical activity more than men of the same age with average body mass index. [Am J Prev Med 1989;5:127-35]
\end{abstract}

Physical activity has been shown to be positively associated with a reduced risk of coronary heart disease and sudden death. Evidence also suggests that physical activity may prevent or help control obesity, hypertension, glucose intolerance, bone loss, and symptoms of anxiety and mild to moderate depression. ${ }^{1-3}$

Despite the importance of physical activity, scant information exists on its long-term determinants. In a recent review of the determinants of physical activity by Dishman et al. ${ }^{4}$ the evidence was derived mainly from intervention studies examining the factors associated with adoption, maintenance, or quitting an exercise program or from cross-sectional studies analyzing the correlation of physical activity with demographic and other factors thought to be

From the Human Population Laboratory, California Public Health Foundation (Lazarus, Cohen, and Leu) and the California Department of Heaith Services (Kaplan), Berkeley.

Address reprint requests to Dr. Lazarus, Human Population Laboratory, California Public Health Foundation, 2151 Berkeley Way, Annex 2, Berkeley, CA 94704. related to the level of physical activity. The conclusions from these studies are limited by the selective nature of the participants and the short follow-up intervals in formal exercise programs and by the problems with causal inference inherent in crosssectional analyses. Few studies have prospectively examined the long-term determinants of physical activity in a community-based sample. ${ }^{5-8}$

Cross-sectional analyses and studies of adherence to exercise programs have indicated that smoking, body mass index, and physical activity may be related. Although the evidence is mixed, there is a suggestion that smoking might have a negative association with physical activity level. ${ }^{9-17}$ In addition, in cross-sectional studies, more active individuals have been found to have a smaller body mass index than those who are sedentary. $, 9,18-20$ Also, there is evidence of a negative association between body mass index and adherence to or maintenance of an exercise program. ${ }^{17}$ However, questions remain as to the causal relationship between smoking and body mass index, on the one hand, and physical activity, on the other. 
Our study was designed to evaluate whether smoking and body mass index were prospectively associated with nine-year (1965-1974) changes in the level of leisure-time physical activity in a representative sample of men and women living in Alameda County, California. Because extensive baseline information, including baseline physical health indicators and demographic information, was available on these individuals, it was possible to adjust for factors that might confound the effect of smoking and body mass index on changes in physical activity.

\section{METHODS}

The data used in these analyses come from the Human Population Laboratory's study of adult residents of Alameda County, California. The details of the study design and sampling method have been reported elsewhere. ${ }^{21,22}$ In 1965 a representative sample of 8,023 noninstitutionalized adults 20 years of age or over (16 years if ever married) were selected. Of these, 6,928 (86\%) completed an extensive questionnaire about behavioral, social, and psychological characteristics as well as health and disease status and functional disabilities. This cohort included 3,158 men and 3,770 women 16-94 years of age.

In 1974, an attempt was made to contact those who had responded in 1965. The vital status of the 1965 respondents was ascertained by means of a computerized record linkage to the State of California's registry of deaths and through attempted contacts with the respondents or references previously supplied by them. Only $302(4.4 \%)$ of the original members were lost to follow-up over this nine-year period. Completed questionnaires were received from $4,864(85.1 \%)$ of the 5,714 surviving respondents who were located. Of these, 4,834 were 20 years of age or over. The analyses reported here are based on the 4,622 individuals 20 years of age or over who were respondents in 1965 and 1974 with no missing values for the leisure-time physical activity index.

We assessed the respondents' baseline physical activity and change in physical activity level using information from 1965 and 1974 responses to the question "Here is a list of things that people do in their free time. How often do you do any of these things?" Table 1 indicates how the four-item leisure-time physical activity index was constructed. It was based on the frequency and presumed strenuousness of the reported leisure-time participation in active sports, swimming and walking, gardening, and exercising. The index equals the sum of the
Table 1. Leisure-time physical activity index

\begin{tabular}{llll} 
& Often & Sometimes & Never \\
\hline Active sports & $4^{a}$ & 2 & 0 \\
Swimming or taking & 4 & 2 & 0 \\
long walks & & & \\
Working in the garden & 2 & 1 & 0 \\
Doing physical exercises & 4 & 2 & 0 \\
\hline
\end{tabular}

Responses weighted to take into account the presumed strenuousness of the activity as well as the frequency of participation.

four items and could range from 0 to 14 . The change in physical activity was calculated to be the 1974 physical activity index minus the 1965 physical activity index and could range from -14 to 14 . Indices of physical activity and change in activity based on these questionnaire activities have been shown to be prospectively associated with mortality risk. ${ }^{21,23-27}$

Categories of current, past, and never smokers were based on responses from 1965 to a series of questions regarding smoking habits. Dummy variables were used to represent current and past smokers with never smokers as the reference category. Weight was self-reported as pounds weighed without heavy clothes and height as inches without shoes. Body mass was represented by body mass index (weight $[\mathrm{lb}] /$ height $^{2}$ [in] $) \times 100$. The distribution of the index was divided into sex-specific quintiles. Dummy variables were used to represent the quintiles in the analyses, with the third quintile as the reference category.

Factors that were thought to be potential confounders of the effect of smoking and body mass index on change in physical activity were also included in the analyses. The 1965 leisure-time physical activity index was included to adjust for the effect of regression to the mean. Because baseline health status might influence subsequent changes in physical activity, health conditions and symptoms from questionnaire information gathered in 1965 were used as covariables. Previous research has also identified a number of demographic, behavioral, and psychosocial variables in the Human Population Laboratory data set that could confound the association between smoking and body mass and the change in physical activity level. Among these are race, education, occupation, family income, marital status, social group membership, ${ }^{28}$ social network index, ${ }^{29}$ depression, ${ }^{30-32}$ life satisfaction, ${ }^{21}$ personal uncertainty, ${ }^{21}$ perceived health, ${ }^{33}$ and energy level.

We first analyzed the sex-specific linear regression models of change in physical activity with baseline smoking status and body mass index as in- 
Table 2. Age- and sex-specific leisure-time physical activity level in 1965 and change in leisure-time physical activity from 1965 to 1974

\begin{tabular}{|c|c|c|c|c|c|c|}
\hline & \multicolumn{3}{|c|}{ Women's age (years) } & \multicolumn{3}{|c|}{ Men's age (years) } \\
\hline & $20-39$ & $40-59$ & $60+$ & $20-39$ & $40-59$ & $60+$ \\
\hline \multicolumn{7}{|l|}{$\begin{array}{l}\text { Physical activity index } \\
\text { in 1965 (range 0-14): }\end{array}$} \\
\hline$n$ & 1,200 & 994 & 364 & 978 & 856 & 230 \\
\hline Mean & 6.42 & 5.23 & 3.84 & 7.00 & 6.07 & 5.26 \\
\hline 25th and 75th percentiles & 4,8 & 3,8 & 2,6 & 5,9 & 4,8 & 2,8 \\
\hline \multicolumn{7}{|l|}{$\begin{array}{l}\text { Change in physical activity } \\
\text { index from } 1965 \text { to } 1974 \text { : }\end{array}$} \\
\hline Mean & 0.18 & -0.24 & -0.62 & -0.13 & -0.22 & -0.49 \\
\hline 25th and 75 th percentiles & $-2,2$ & $-2,2$ & $-2,1$ & $-2,2$ & $-2,2$ & $-2,2$ \\
\hline
\end{tabular}

dependent variables, controlling for age and baseline physical activity. Then we examined a set of models, controlling for baseline physical health characteristics. Health conditions and symptoms that we found to be independent predictors of physical activity change or that appeared to confound the association between change in physical activity and the predictors, smoking and body mass index, in regression models were retained in the subsequent models. Finally, we added demographic, behavioral, and psychosocial variables to the models. A dose-response relationship between change in physical activity and pack-years of smoking was evaluated by examining a model that included dummy variables for current and past smoking, a continuous term for pack-years of smoking, and the interactions between these variables. We evaluated age- and sex-specific models for persons $20-39,40-59$, and 60 years of age and over to further clarify the association of body mass index, smoking, and change in level of physical activity at different ages. We tested apparent interactions between age and smoking and age and body mass suggested by the age- and sex-specific regression models using a two-way analysis of variance.

\section{RESULTS}

The mean baseline physical activity index and change in level of physical activity for women and men in three age groups are shown in Table 2. The mean levels of physical activity are higher for men than women in all three age groups and decrease with age among both men and women.

Examination of the nine-year change in physical activity indicates that, except in the youngest women (20-39 years of age), there was a tendency for the activity level to decrease over the follow-up period. This is represented by the negative values for mean change seen in Table 2. Although the

Table 3. Association of smoking and body mass with change in leisure-time physical activity

\begin{tabular}{|c|c|c|c|c|}
\hline \multirow[b]{2}{*}{ Variable } & \multicolumn{2}{|c|}{ Women $(n=2,492)$} & \multicolumn{2}{|c|}{$\operatorname{Men}(n=2,028)$} \\
\hline & $\begin{array}{l}\text { Regression } \\
\text { coefficient }\end{array}$ & $95 \% \mathrm{CI}$ & $\begin{array}{l}\text { Regression } \\
\text { coefficient }\end{array}$ & $95 \% \mathrm{CI}$ \\
\hline $\begin{array}{l}\text { Intercept } \\
\text { Age in } 1965 \\
\text { Baseline physical activity index } \\
\text { Current smokers } \\
\text { Past smokers }\end{array}$ & $\begin{array}{r}4.63 \\
-0.05 \\
-0.49 \\
-0.27 \\
0.19\end{array}$ & $\begin{array}{l}(4.13,5.13) \\
(-0.05,-0.04) \\
(-0.52,-0.45) \\
(-0.50,-0.05) \\
(-0.15,0.53)\end{array}$ & $\begin{array}{r}4.72 \\
-0.04 \\
-0.52 \\
-0.26 \\
0.09\end{array}$ & $\begin{array}{l}(4.11,5.32) \\
(-0.05,-0.03) \\
(-0.56,-0.48) \\
(-0.54,0.02) \\
(-0.25,0.43)\end{array}$ \\
\hline $\begin{array}{l}\text { Body mass index quintiles } \\
\text { 1 } \\
2 \\
4 \\
5\end{array}$ & $\begin{array}{l}0.33 \\
0.52 \\
-0.09 \\
-0.70 \\
\text { Adjusted } r^{2}\end{array}$ & $\begin{array}{l}(0.00,0.66) \\
(0.19,0.85) \\
(-0.42,0.25) \\
(-1.04,-0.36) \\
.25\end{array}$ & $\begin{array}{l}-0.12 \\
-0.04 \\
0.33 \\
-0.16 \\
\text { Adjusted } r^{2}\end{array}$ & $\begin{array}{l}(-0.50,0.26) \\
(-0.41,0.34) \\
(-0.05,0.71) \\
(-0.54,0.22) \\
26\end{array}$ \\
\hline
\end{tabular}

a Reference group for smoking is never smokers.

beference group for body mass index is quintile 3. 
change in physical activity is symmetrically distributed between -14 and 14 , most of the changes in the index are small, with the middle $50 \%$ of the distribution concentrated between -2 and 2 for both sexes at all ages.

The results of the linear regression model estimation of change in leisure-time physical activity as a function of age, baseline physical activity, smoking, and body mass index are shown in Table 3. For categorical variables, such as smoking or body mass index, these regression coefficients represent the mean difference in change in physical activity between two risk groups, for example, current compared to never smokers. For continuous variables, such as age, the regression coefficient represents the mean difference in change in level of activity per unit of the variable (e.g., per year of age or per unit of the baseline physical activity index).

For women, the mean difference between current and never smokers in change in physical activity level is -0.27 units ( $95 \%$ confidence interval $[\mathrm{CI}]=$ -0.50 to -0.05$)$. For men, the mean difference is $-0.26(95 \% \mathrm{CI}=-0.54$ to 0.02$)$. For both women and men, the mean difference in change in physical activity level for past smokers compared to never smokers is not significant $(95 \% \mathrm{CI}=-0.15$ to 0.53 for women and -0.25 to 0.43 for men), presumably reflecting the heterogeneity of the past smoker group.

To test the dose-response relationship between physical activity change and smoking, we examined a regression model with dummy variables for current and past smoking and product terms for the interaction between current and past smoking status and pack-years of exposure. For female current smokers, increasing exposure is significantly associated with an increasing decline in the level of physical activity $(P=.02)$. For example, the mean change in physical activity level for female current smokers with 10 pack-years' exposure is -0.15 units, and for those with 40 pack-years exposure, it is -0.60 units. In male current smokers, there is less reliable evidence for a dose response $(P=.06)$. There is no evidence for a dose response among either male or female past smokers.

In Table 3, the regression coefficients for men and women are very similar, except those for body mass index. Compared to those in quintile 3 , the women in quintiles 1 and 2 have increases in activity level (coefficient $=0.33,95 \% \mathrm{CI}=0.00$ to 0.66 for quintile 1 ; coefficient $=0.52,95 \% \mathrm{CI}=0.19$ to 0.85 for quintile 2). Women in quintile 5 have large decreases in activity compared to those in quintile 3. The average difference is -0.70 units $(95 \% \mathrm{CI}=$ -1.04 to -0.36$)$. For men, there is no consistent
Table 4. Estimated mean change ${ }^{a}$ in leisure-time physical activity level from 1965 to 1974 for those of average body mass at 30,50 , and 70 years of age by smoking status

\begin{tabular}{lccc} 
& $\begin{array}{l}\text { Never } \\
\text { smokers }\end{array}$ & $\begin{array}{l}\text { Past } \\
\text { smokers }\end{array}$ & $\begin{array}{l}\text { Current } \\
\text { smokers }\end{array}$ \\
\hline $\begin{array}{l}\text { Women }(n=2,492) \\
30\end{array}$ & & & \\
50 & -0.09 & 0.28 & -0.18 \\
70 & -0.43 & -0.24 & -0.71 \\
Men $(n=2,028)$ & & & \\
30 & 0.09 & 0.18 & -0.18 \\
50 & -0.20 & -0.11 & -0.46 \\
70 & -0.43 & -0.35 & -0.70 \\
\hline
\end{tabular}

a Estimated mean change is calculated using the intercept and variable coefficients shown in Table 3 . Baseline physical activity is set at the mean level for women and men 25-35, 45-55, and 65-75 years of age. Quetelet index is set at quintile 3 .

relationship between body mass index and change in physical activity.

Estimated mean changes in leisure-time physical activity were calculated for women and men 30,50, and 70 years of age by smoking status (Table 4 ) using the intercept and variable coefficients shown in Table 3. For these calculations, baseline physical activity index was set at the mean level for women and men $25-35,45-55$, and $65-75$ years of age. For both sexes, the body mass index was set at the third quintile. Note that the age-, sex-, and smoking-specific means are adjusted for baseline activity and body mass.

The estimated mean change in leisure-time physical activity level for a 30-year-old nonsmoking woman is only 0.09 units, representing a very small increase in activity from 1965 to 1974. In contrast, the mean change in leisure-time physical activity level for a 70-year-old woman smoker is -0.71 units, which represents a decline in physical activity. Current smokers at each age show the greatest decline in physical activity level. Younger never and past smokers show small increases in physical activity level.

Table 5 shows the estimated change in leisuretime physical activity level by body mass quintile for women and men 30,50, and 70 years of age. Estimated mean changes for never smokers were calculated using the model coefficients presented in Table 3 with the baseline physical activity index set at the mean level for women and men 25-35, $45-55$, and $65-75$ years of age. For women, there is a decreasing mean physical activity change from the second quintile through the fifth, indicating that there is either less increase or more decline in physical activity associated with larger 1965 body mass index. Younger women with smaller body mass 
Table 5. Estimated mean change $\mathrm{e}^{a}$ in leisure-time physical activity level from 1965 to 1974 for never smokers at 30,50, and 70 years of age by body mass

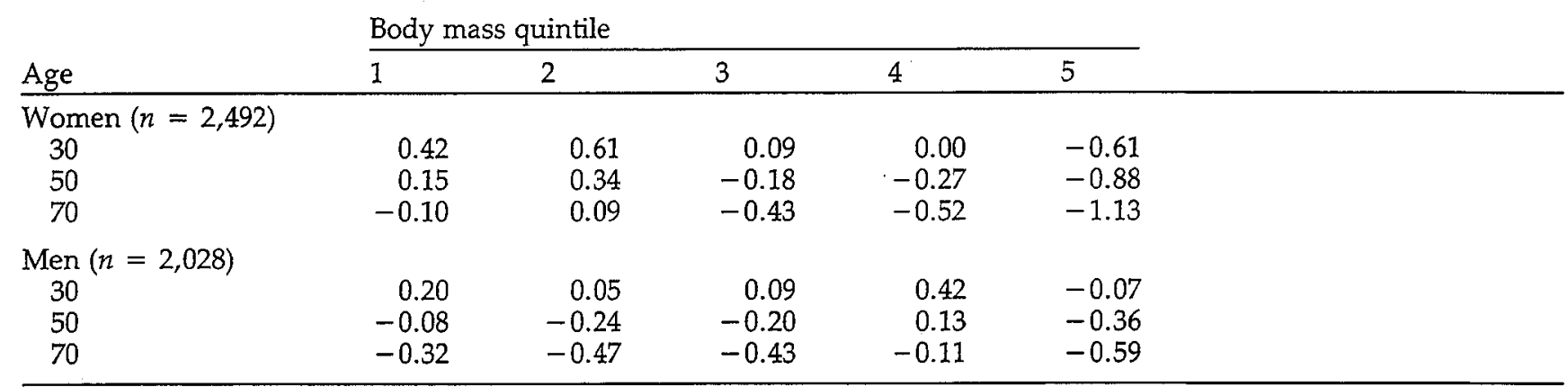

a Estimated mean change is calculated using the intercept and variable coefficients shown in Table 3. Baseline physical activity is set at the mean level for women and men $25-35,45-55$, and $65-75$ years of age.

index have slight increases in physical activity level from 1965 to 1974.

Among women, the associations between change in physical activity and the predictors, smoking and body mass index, were not altered by adjusting for sociodemographic variables such as race, family income, and education or by adjusting for psychosocial variables such as social networks, depression, personal uncertainty, and life satisfaction. With one exception, adjustment for health characteristics had no effect on these associations. Adjustment for pulmonary symptoms and conditions (frequent coughs and colds, trouble breathing, and chronic bronchitis) decreased the association between smoking and activity change by $33 \%$.

Among men, adjustment for education reduced the association between smoking and activity change by $30 \%$. None of the other covariables mentioned above substantially changed this association.

In the preceding analysis, the effects of smoking and body mass on activity change were assumed to be the same at all ages. Sex- and age-specific $(20-39,40-59$, and 60 years of age and over) re- gression analyses suggest that this assumption may be true for smoking but not for body mass. To test for an interaction between age and smoking a twoway analysis of variance, adjusted for baseline activity and body mass index, was carried out, with age and smoking categorized in the three groupings used in the age-specific regression analyses. The $F$ test does not indicate an interaction between age and smoking for women $(P=.65)$ or for men $(P=$ $.52)$.

In the sex- and age-specific regression analyses, the relationship between body mass and activity change, adjusted for baseline activity, and smoking, did vary with age for men more than for women. To test these apparent interactions, a twoway analysis of variance was used with age in three categories and body mass index in sex-specific quintiles. The analysis was adjusted for baseline physical activity and smoking. The F-tests for the age-body mass interaction were statistically significant for women $(P=.04)$ and for men $(P=.01)$.

Table 6 shows sex- and age-specific coefficients that compare the first, second, fourth, and fifth

Table 6. Coefficients ${ }^{a}$ for the association between change in leisure-time physical activity and body mass by sex and age

\begin{tabular}{lccccccc} 
& \multicolumn{3}{c}{ Women's age (years) } & & \multicolumn{3}{c}{ Men's age (years) } \\
\cline { 2 - 4 } \cline { 6 - 7 } Body mass quintile & $20-39$ & $40-59$ & $60+$ & & $20-39$ & $40-59$ & $60+$ \\
\hline 1 & 0.50 & 0.21 & 0.17 & & $0.46^{c d}$ & $-0.65^{c}$ & $-1.54^{d}$ \\
2 & $0.71^{b}$ & 0.44 & $-0.31^{b}$ & & $0.10^{e}$ & $0.13^{f}$ & $-1.35^{\text {ef }}$ \\
4 & -0.43 & -0.03 & 0.19 & & 0.42 & 0.26 & 0.12 \\
5 & -0.64 & -0.99 & -0.26 & 0.05 & -0.25 & -0.76 \\
\hline
\end{tabular}

a Coefficients measure estimated mean difference in physical activity change between each quintile and quintile 3 and are estimated from two-way analyses of variance. Coefficients that differ significantiy between age groups, contributing to the interaction between age and body mass, are marked as follows:

${ }^{\circ} P=.08$.

$\therefore P=.008$

d $P=.005$

e $P=.03$ 
body mass quintiles to the third quintile, estimated from the two-way analysis of variance. The coefficients that are found to differ significantly across age groups are marked (see footnote to Table 6). For women, only the coefficients comparing the second quintile of body mass to the third quintile differ significantly between age groups $20-39$ and 60 years and over. The younger, leaner women increased their physical activity more than those of average body mass index while the older women in quintile 2 decreased their activity more than those of average body mass index. Otherwise, the age-specific effects of body mass are essentially similar to those for all women presented in Table 3 .

For men, the relation of body mass to physical activity change has a stronger age-related pattern (Table 6). The coefficients comparing the first and second quintiles to the third differ significantly among the three age groups. The older and middleaged, leaner men decreased their activity while the younger, leaner men increased their activity more than those in the third quintile.

Because the apparent association of leanness with decreased activity in middle-aged and older men could be due to preexisting disease, variables including symptoms of lung and heart disease, conditions including diabetes and cancer, and self-perception of health status were added to the models to adjust for the effect of illness. Although reduced, the association between underweight and activity decline persists after adjustment for these factors.

\section{DISCUSSION}

The effects of smoking status and body mass index on change in leisure-time physical activity over the nine-year period from 1965 to 1974 were studied in a prospective community-based study of Alameda County adults. Both women and men who were current smokers in 1965, compared to those who were nonsmokers, experienced a greater decline in leisure-time physical activity level.

Among men, part of the association between smoking and the decline in physical activity reflects the confounding effect of education. That is, men who are current smokers tend to have less education, and less education is associated with a greater decline in physical activity.

The results of the age-specific analyses suggest apparent age-dependent relationships between body mass and physical activity change. For both sexes, being lean was associated with an increase in activity at younger ages, but at older ages was associated with a decline. For women, the increases in activity seen in young, lean women were signifi- cantly greater than those seen in those of average body mass. At all ages, the heaviest women and men experienced a decline in leisure-time physical activity. For women only, the decline in activity of the heaviest group was significantly greater than that for those of average body mass.

Older, lean men, even after adjustment for baseline health status, decreased their activity more than men of average body mass. When the effects seen in lean men are averaged over age groups, the age-dependent associations between body mass and physical activity change are obscured.

There are several ways in which smoking and body mass could effect a change in level of physical activity. It may be that constitutional and genetic factors are important determinants of both body mass and the tendency to engage in physical activity. Thus, a common factor such as body composition or aerobic capacity might predispose one to be both overweight and physically inactive. A standard activity may be harder, on both an actual and perceived level, for the heavier and less physically fit person. This would influence the observed association between body mass at baseline and the subsequent change in physical activity.

In addition, positive health behaviors may vary together. Thus health-conscious individuals who smoke less and eat more prudently may be more likely to increase (or decrease less) their physical activity.

Another way smoking and body mass could influence changes in physical activity level is through adverse health effects that result in decreases in activity. For instance, one may postulate that smoking produces health problems that reduce the desire or ability to participate in physical activity, resulting in a decline in level over the follow-up period. For women, this appeared to be true. Smoking was associated with the report of pulmonary symptoms including frequent coughs and colds, trouble breathing, and bronchitis among both men and women. However, only among women did the presence of these symptoms have an independent association with a change in physical activity. Among women, adjustment for pulmonary symptoms reduced the association between smoking and change in physical activity by $34 \%$. In contrast, the presence of pulmonary symptoms among men was not associated with a greater decline in physical activity and thus does not explain the association of smoking with a change in physical activity.

The differences between women and men in the relationship among smoking, pulmonary disease, and change in physical activity may be due to differences in smoking habits or to differences in re- 
porting health symptoms or physical activity level. Further analyses do not substantiate either of the above explanations. In age-adjusted analyses, men were found to have smoked more years and more packs per day; men thus have more pack-years of exposure than women. Therefore, women would not be expected to have more severe symptoms than men because of smoking, unless smoking affects women more severely. In addition, smoking status is more closely related to the prevalence of self-reported pulmonary symptoms among men than among women. For the three reported symptoms of frequent colds and cough, trouble breathing, and chronic bronchitis, the relative risks associated with these symptoms in current compared to never smokers were $2.66,1.52$, and 2.20 , respectively, among women, and $3.81,2.71$, and 3.34 , respectively, among men.

The possibility that change in physical activity is more accurately reported by women than men was tested by examining the association between the incidence of heart trouble and chest pain from 1965 to 1974 in relation to changes in the physical activity index during the same period. Among both women and men, the incidence of heart pain or heart trouble was associated with a decline in physical activity. The mean difference in physical activity change between those with and without incidence of heart trouble was -0.55 units among women and -0.56 among men. For incidence of heart pain, the mean differences in physical activity change were smaller and of about equal magnitude among both women and men. Thus we have no evidence that men report health symptoms or change in physical activity less accurately than women.

Although the study reported here has several advantages over past research, including its prospective design and length of follow-up, there are several disadvantages. The leisure-time physical activity index is constructed from self-reports of swimming, walking, gardening, exercising, and participation in active sports only. Furthermore, we do not know the exact frequency or duration per week of these activities. We also have no information about the amount of activity at work for those who were employed. In addition, there is no information about levels of fitness or endurance.

In spite of these deficiencies in the four-item activity index, the validity of this measure is demonstrated by its ability to predict important health outcomes. A similar index, and changes in it, have been found to be associated with all-cause mortality and ischemic heart disease mortality in the Alameda County Study's 1965 and 1974 cohorts. ${ }^{21,23-27,34}$ Earlier studies by Wingard et $a .^{26}$ and Wingard and
Berkman $^{34}$ of the nine-year mortality risk of being inactive compared with active used a five-item measure of leisure-time physical activity that included hunting and fishing activities in addition to the four items used in this study. Their study of men and women 30-69 years of age in 1965 revealed significantly elevated odds ratios ranging from 1.4 to 1.7 , depending on the adjustment factors included in the model. In a later study by Kaplan et al., ${ }^{24}{ }^{17-}$ year mortality risk was also associated with the same five-item leisure-time activity index. In agestratified analyses, adjusting for baseline physical health status and other behavioral factors such as smoking and relative weight, odds ratios comparing the inactive to the active were 1.48, 1.27, 1.38 , and 1.37 in those $38-49,50-59,60-69$, and 70 years of age and over. A recent study of ischemic heart disease mortality by Kaplan et al. ${ }^{27}$ also reveals an elevated nine-year risk in both the 1965 and 1974 Alameda County Study cohorts. In addition, a study of the changes in leisure-time physical activity $^{25}$ using a three-item index (excluding gardening, hunting, and fishing) was completed in 1965 for those 50-94 years of age who were free of important baseline health symptoms and conditions. Those who increased their physical activity from 1965 to 1974 had a lower risk of subsequent nine-year mortality than those who decreased their activity.

The results of our study provide evidence that different levels of one risk factor are associated with changes over time in another risk factor. The result of such a pattern of interrelated associations is that a risk factor such as smoking will have two kinds of effects on health: those that act directly (e.g., pathophysiologically) and those that act indirectly through changes in a related risk factor. These observations have at least two important implications. First, they suggest that a salutary intervention aimed at one risk factor might also result in a beneficial effect on the future level of a second risk factor. Second, as a methodologic point, they suggest that estimates of the effect of a single risk factor in a cohort study will be biased to the extent that the risk factor is associated with changes over time in other important risk factors. Only prospective studies with multiple waves of data collection will be able properly to take into account the effects on risk estimation of such complicated causal pathways.

This study was conducted at the Human Population Laboratory, California Department of Health Services, Berkeley, California. The research was supported by a grant from the National Institute on Aging (AG05903). 


\section{REFERENCES}

1. Powell KE, Paffenbarger RS. Workshop on epidemiologic and public health aspects of physical activity and exercise: a summary. Public Health Rep 1985;100:118-26.

2. Paffenbarger RS, Hyde RT. Exercise in the prevention of coronary heart disease. Prev Med 1984;13:3-22.

3. Siscovick DS, LaPorte RE, Newman JM. The diseasespecific benefits and risks of physical activity and exercise. Public Health Rep 1985;100:180-8.

4. Dishman RK, Sallis JF, Orenstein DR. The determinants of physical activity and exercise. Public Health Rep 1985;100:158-72.

5. Paffenbarger RS, Hyde RT, Wing AL, Steinmetz $\mathrm{CH}$. A natural history of athleticism and cardiovascular health. JAMA 1984;252:491-5.

6. Stephens KE, Van Huss WD, Olson HW, Montoye HI. The longevity, morbidity, and physical fitness of former athletes - an update. In: Eckert HM, Montoye HJ; eds. The American Academy of Physical Education papers; no. 17, Exercise and health. Champaign, Illinois: Human Kinetics Publishers, 1984:101-19.

7. Powell KE, Dysinger W. Childhood participation in organized school sports and physical education as precursors of adult physical activity. Am J Prev Med 1987;3:276-81.

8. Sallis JF, Haskell WL, Fortmann SP, et al. Predictors of adoption and maintenance of physical activity in a community sample. Prev Med 1986;15:331-41.

9. Blair SN, Jacobs DR, Powell KE. Relationships between exercise or physical activity and other health behaviors. Public Health Rep 1985;100:172-80.

10. Langlie JK. Interrelationships among preventive health behaviors: a test of competing hypotheses. Public Health Rep 1979;94:216-25.

11. Harris $L$ et al. Fitness in America - the Perrier study: a national research report of behavior, knowledge, and opinions concerning the taking up of sports and exercise. New York: Garland, 1984.

12. Sedgwick AW, Brotherhood JR, Harris-Davidson A, Kaplin RE, Thomas DW. Long-term effects of physical training programme on risk factors for coronary heart disease in otherwise sedentary men. Br Med J 1980;281:7-10.

13. Epstein L, Miller GJ, Stitt FW, Morris JN. Vigorous exercise in leisure time, coronary risk-factors, and resting electrocardiogram in middle-aged male civil servants. $\mathrm{Br}$ Heart J 1976;38:403-9.

14. Bjartveit $\mathrm{K}$, Foss OP, Gjervig T. The cardiovascular disease study in Norwegian countries: results from first screening. Acta Med Scand 1983;675(suppl):95-130.

15. Holme I, Helgeland A, Hjermann I, Leren P, LundLarsen PG. Physical activity at work and at leisure in relation to coronary risk factors and social class: a 4-year mortality follow-up. The Oslo Study. Acta Med Scand 1981;209:277-83.
16. Hickey N, Mulcahy R, Bourke GJ, Graham I, WilsonDavis K. Study of coronary risk factors related to physical. activity in 15,171 men. Br Med J 1975;3:507-9.

17. Dishman RK. Compliance/adherence in health-related exercise. Health Psychol 1982;3:237-67.

18. Montoye H]. Physical activity and health: an epidemiologic study of an entire community. Englewood Cliffs, New Jersey: Prentice-Hall, 1975:95.

19. Folsom AR, Caspersen CJ, Taylor HL, et al. Leisure time physical activity and its relationship to coronary risk factors in a population-based sample: the Minnesota Heart Survey. Am J Epidemiol 1985;121:570-9.

20. Epstein LH, Wing RR. Aerobic exercise and weight. Addict Behav 1980;5:371-88.

21. Berkman LF, Breslow L. Health and ways of living: The Alameda County Study. New York: Oxford University Press, 1983.

22. Hochstim JR. Health and ways of living-the Alameda County, California, population laboratory. In: Kessler II, Levin ML, eds. The community as an epidemiologic laboratory. Baltimore: Johns Hopkins University Press, 1970:149-76.

23. Kaplan GA, Haan MN. Is there a role for prevention among the elderly? Epidemiologic evidence from the Alameda County Study. In: Ory MG, Bond $\mathrm{K}$, eds. Aging and health care: social science and policy perspectives. London: Tavistock (in press).

24. Kaplan GA, Seeman TE, Cohen RD, Knudsen LP, Guralnik J. Mortality among the elderly in the Alameda County Study: behavioral and demographic risk factors. Am J Public Health 1987;77:307-12.

25. Haan MN, Kaplan GA, Cohen RD, Knudsen LP. Risk factor change and all-cause mortality in older persons: evidence from the Alameda County Study. Presented at the Annual Meeting of the Society for Epidemiologic Reseach, Pittsburgh, Pennsylvania, June 1986.

26. Wingard DL, Berkman LF, Brand RJ. A multivariate analysis of health-related practices: a nine-year mortality follow-up of the Alameda County Study. Am J Epidemiol 1982;116:765-75.

27. Kaplan GA, Cohn BA, Cohen RD, Guralnik J. The decline in ischemic heart disease mortality: prospective evidence from the Alameda County Study. Am J Epidemiol 1988;127:1131-42.

28. Seeman TE, Kaplan GA, Knudsen L, Cohen R, Guralnik J. Social network ties and mortality among the elderly in the Alameda County Study. Am J Epidemiol 1987;126:714-23.

29. Berkman LF, Syme SL. Social networks, host resistance, and mortality: a nine-year follow-up study of Alameda County residents. Am J Epidemiol 1979;109:186204.

30. Kaplan GA, Roberts RE, Camacho TC, Coyne JC. Psychosocial predictors of depression: prospective evidence from the Human Population Laboratory studies. Am J Epidemiol 1987;125:206-20. 
31. Roberts RE, $\mathrm{O}^{\prime}$ Keefe SJ. Sex differences in depression reexamined. J Health Soc Behav 1981;22:394-400.

32. Roberts RE. Prevalence of depressive symptoms among Mexican Americans. J Nerv Ment Dis 1981; 169:213-9.

33. Kaplan GA, Camacho T. Perceived health and mor- tality: nine-year follow-up of the Human Population Laboratory cohort. Am J Epidemiol 1983;117:292-304.

34. Wingard D, Berkman LF. A multivariate analysis of health practices and social networks. In: Berkman LF, Breslow L, eds. Health and ways of living: the Alameda County study. New York: Oxford University Press, 1983:161-75. 
